\title{
Experimental investigation of DI diesel engine fuelled by biodiesel with Nano additives
}

\author{
R. Rajasekar ${ }^{* *}$ and P. Naveenchandran ${ }^{2}$ \\ Research Scholar, Department of Automobile Engineering, Bharath Institute of Higher Education \& Research, \\ Chennai, Tamilnadu, India ${ }^{1}$ \\ Professor, Department of Automobile Engineering, Bharath Institute of Higher Education \& Research, Chennai, \\ Tamilnadu, India ${ }^{2}$
}

Received: 27-October-2020; Revised: 26-November-2020; Accepted: 28-November-2020

(C)2020 R. Rajasekar and P. Naveenchandran. This is an open access article distributed under the Creative Commons Attribution (CC BY) License, which permits unrestricted use, distribution, and reproduction in any medium, provided the original work is properly cited.

\begin{abstract}
The demand for fuel is increasing everyday life and its risks poses a serious problem to this globalization. It is an unprecedented alternative fuel source for biodiesel designed to increase the value of fossil fuels and increase the longevity and purity of the diesel engine. The origin of fossil fuels will decrease in the coming years, besides, the price and demand for fuel will be rare. The negative environmental barrier prompted researchers to find alternative fuels for fossil fuels. Biodiesel from watermelon seed oil (WSO) had a lot of appeal and could be a different alternative to diesel without any mechanical modifications. This will help protect the environmental status of crude oil in oil imports, which is expected to increase by $82 \%$ by 2020. The present study focuses on the comparative behavior of B20 [1], which is zirconium dioxide (ZrO2) with various nanoparticles. In some cases, Zirconia is the white crystalline oxide of Zirconia, so it's most natural form with a monoclinic crystal structure is batiste ore. Zirconium dioxide (ZrO2) with $20 \%$ watermelon seed oil biodiesel $+80 \%$ diesel (B20). The compounds were mixed with 20 particles per million (ppm), 40 ppm, B20 with 60 ppm and B20 with a magnetic motion for 30 min, followed by sonication of the nanoparticles for 30 min, respectively. Biodiesel compounds at a B20 ratio in diesel fuel increase efficiency and reduce emissions of hydrocarbons, carbon monoxide and smoke due to the emission of nitrogen oxides due to better combustion properties. Criticisms conclude that additional applications of biodiesel are best for improving combustion efficiency and reducing emissions.
\end{abstract}

\section{Keywords}

Diesel, Bio diesel, Zirconium dioxide, Performance, Emission parameters.

\section{Introduction}

\subsection{Crude oil}

One of the major drawbacks of crude oil is the largescale emissions that are directly related to pollution and other social problems of the environment. Oil reserves are found all over the world, including the North Sea, the Saudi Arabian Peninsula and Russia and other countries are the United States, Iran, Iraq and China. Currently, the annual energy consumption of the world is about 12.2 Mega Tons of crude oil. It is estimated that energy consumption will rise to 1.749 Mega Tons of oil by 2035. Southeast Asia's energy needs alone will increase by about $75 \%$ by 2030, based on the economic growth trends of China and India. Oil is increasing day by day in our world.

*Author for correspondence

182
Many people around the world, their researchers and scientists are looking for alternative diesel fuel. The harm of crude oil is a source of renewable energy. Combustion oil produces carbon dioxide, and burning oil pollutes the air [2].

We have to import a large portion of our oil and it becomes more and more expensive as stocks and imports increase. The greatest deficiency of oil, which has been retained for millions of years, is in the carcasses of plants and animals. This carbon transfer from the Earth to the environment has the effect of global warming. So this is the main reason for choosing biodiesel.

\subsection{Biodiesel and preparation}

Biodiesel is a type of diesel fuel of vegetable or animal origin that contains long chain fatty acid esters. It is commonly formed by chemical reactions 
of fats such as animal fats (high), soybean oil or some other alcoholic vegetable oil, resulting in a methyl, ethyl or propane ester. Unlike petroleum, which is based on biodiesel, diesel, it is a renewable energy source [3, 4]. Biodiesel is less pollutant than petroleum diesel, and the less content of sulphur of sulfur in $100 \%$ biodiesel extends the life of modified catalysts. Biodiesel can be mixed with oils from other energy sources. Among the biodiesel products, watermelon seeds are selected and the scientific name for watermelon seeds is Citralus lanatus, [5] which is a small plant belonging to the cockroach family, and watermelons are grown in tropical and subtropical climates around the world. The sweet and juicy pulp is usually dark red to pink in color, with many black seeds. It has established itself as an invasive weed in Africa, Asia and Australia and is a factor in the continued spread of malaria, especially when there are no sources of sugar in the mosquito's own plant during drought. Sweet melons are edible and nutritious from the pods. It can be raw, boiled, stored, ground or fermented to make mild alcohol. Species use includes fodder, wood and some environmental management [6]. Watermelon seeds were collected and washed in water for cleaning [7, 8]. They were then manually removed from the fruit for two weeks after drying in the sun. The dried seeds are placed in an oven and roasted at about $25^{\circ} \mathrm{C}$ for 24 hours [9]. When seeds were dry, they were rumpled into small pieces. The seeds are dried and then ground into small pieces. Used to extracting for chocolate oil. The sample was taken with a finger made of thick cotton placed in the main chamber of the socks let machine. Hexane was used as the solvent in the extract. The steam filter rises in the hand and falls into the active housing. The room with the melon seeds is broken down and gradually charged with a wet solvent. When the socks let chamber was almost finished, one side of the siphon immediately dried it, and the solvent was returned to the filter jar [10].

\subsection{Problem of bio diesel}

Consumers utilizing biodiesel fuel also identified many of the issues. Careful analysis shows that most of these difficulties can be traced to biodiesel fuel of poor quality and are almost similar to the problems caused by petroleum diesel of low quality. Some of the issues (primarily problems with cold weather) aren't due to poor fuel efficiency, but are linked to the intrinsic properties of biodiesel. Growing engine issues are discussed below when utilizing biodiesel, the possible causes, and their solutions. Deposits on injector impact pattern of fuel release. The most common symptoms are either misfiring or beginning fast [11]. This is most likely caused either by coldweather activity with partly solidified gasoline, or by fuel not fully converted from oil to biodiesel. Vegetable oil appears to develop deposits on the injectors, particularly when the engine runs at part load. Have the injectors cleaned by a trained mechanic the precise nature of the injectors makes it difficult to clean certain pieces unless you have specialized training and facilities. In cold conditions, low-temperature flow-improving additives can be used to boost fuel activity and to help avoid this problem in the future. The most common problem with fuel quality is the biodiesel may well contain some unconverted vegetal oil (incomplete processing). Trace of chemicals from the making if biodiesel from the seeds (e.g. Methanol) can keep on in biodiesel. Produces of the reaction (eg. Glycerin, soaps) may not be completed.

\subsection{Biodiesel with additives}

The synthesis of various chemical additives is widely used for automotive fuels to improve the quality of biodiesel fuel and diesel fuel to convene the most desirable level of performance. Additives should help the oil restore its environmental standards in terms of engine efficiency, output and pollution [12]. The collection of additives will be focused on the disadvantages of biodiesel fuel such as density, toxicity, viscosity, and economic viability, solubility of additives, auto- ignition speed, and flash point and a certain amount of the fuel mixing process. The fuel additive concentration is not controlled [13]. Harmful emission from fuel combustion, Developing the combustion performance and properties of fuel, Engine protection and cleanliness, saving the fuel from engine economic and performance, enhanced the nagging properties and immovability of the fuel. Saving the fuel from engine economic and fuels they are many types of nanoparticle additives are aluminium oxide, magnesium oxide, zirconium dioxide, titanium dioxide, cerium oxide, zinc oxide etc., In this project we are going to addition of zirconium dioxide in the form of $20 \mathrm{ppm}, 40 \mathrm{ppm}$, and $60 \mathrm{ppm}$. The addition of additive done ultrasonication process for 30 minutes to reduce the emission parameters after the process, we obtained the B20 with Nano additives [14]. Table 1 shows the properties of fuel. 
Table 1 Properties of fuel

\begin{tabular}{lll}
\hline Fuel & Calorific Value $(\mathbf{k J} / \mathbf{k g})$ & Density, $\mathbf{( K g} / \mathbf{m} 3)$ \\
\hline B100 & 34502.17 & 906 \\
\hline B80 & 36161.736 & 893.36 \\
\hline B60 & 37821.302 & 880.72 \\
\hline B40 & 39480.868 & 868.08 \\
\hline B20 & 41140.434 & 855.44 \\
\hline Diesel (B0) & 42800 & 842.8 \\
\hline
\end{tabular}

\section{Literature review}

Asokan et al. [11] In this article, this research focuses on produced biodiesel. The process of crossesterification followed by an alkaline esterification process yielding $80 \%$ of juliflora oil (JFO) WITH $20 \%$ of methyl ester. Experiments were performed on a 1-cylinder diesel engine using JFO biodiesel and diesel blends. The experimental results for the fuel mixture of various blends of 20,30,40, and $100 \%$ were compared with those for the diesel (B100). The results indicated the performance and combustion characteristics of the B20 enema more in line with the trend of diesel fuel. Brake specific fuel consumption (BSFC) for the B20 and B30 mixture $(0.27 \mathrm{~kg} / \mathrm{kWh})$ at full load was closer to that of diesel $(0.26 \mathrm{~kg} / \mathrm{kWh})$. The proportion of BTE to Juliflora Biodiesel B100 is $31.11 \%$ and was closer to diesel $(32.05 \%)$ at full load.

Bafghi et al. [14] In this study, the effect of ethanol and diesel mixtures with different types of additives on performance and exhaust emissions was experimentally studied using experimental modeling and optimization methods. The experiments are conducted on a turbocharged Common Rail Direct Injection engine. Engine Performance Enhancement (MXEE + CE) with Ethanol is superior to 47 other additives. Optimal conditions were found to be NE, $\mathrm{MN}$, engine speed and load $1500 \mathrm{rpm}$ and 48167.8 $\mathrm{Nm}$, respectively. Under these conditions, the model estimated the soot content, the formation of 49 nitrogen oxides and carbon dioxide, and the specific consumption of brake fuel (BSFC) and energies of 27.59, 441.23, $28.91 \mathrm{ppm}$. The modeling and modeling techniques established can be used as a useful tool to design and optimize suitable ethanol and diesel fuels with efficient performance for various industrial applications.

Ghanbari et al. [15] the performance and exhaust emissions of a diesel engine powered by fuel mixed with nano-diesel and biodiesel were examined. Multiwalled carbon nanotubes (40, 80 and 120 particles per million) and silver nanoparticles (40, 80 and 120 $\mathrm{ppm})$ were produced and added to the blended 184 biodiesel. The optimal models were selected conferring to the statistical criteria for root mean square error (RMSE) and factor of determination (R2). It was observed that the GP model could predict engine performance and emission parameters with a correlation coefficient (R2) in the range 0.928 1 and found the RMSE to be close to zero. The simulation results showed that the GP model is a good tool for predicting drive IC performance and emission parameters.

Prabakaran and Udhoji [2] this study aims to investigate the effect of adding zinc oxide nanoparticles to mixtures of ethanol, biodiesel and biodiesel. Among the six mixtures, the properties of two mixtures have been tested according to ASTM standards. Performance tests were conducted on a single-cylinder, four-stroke direct injection diesel engine at a constant speed of 1,500 rpm. This study gives a trend to use renewable fuels to reduce fossil fuel consumption. The addition of zinc oxide nanoparticles increased BTE and reduced BSFC compared to the full load biodiesel ethanol blend. This study gives a trend to use renewable fuels to reduce fossil fuel consumption.

\section{Experimental setup}

The configuration consisted of a four-stroke singlecylinder diesel engine connected to a charge-AD dynamometer. Instruments are fitted to measure combustion pressure and crankshaft angle. These signals are connected to the system via the motor size of a diesel engine connected to a single-cylinder, four-stroke configuration and a load-type ADcurrent-type dynamometer. The arrangement of the experimental setup is shown in Figure 1. Instruments are fitted to measure combustion pressure and crankshaft angle. The details of the engine specification are given in Table 2. These signals are connected to the computer via the size of the P $\theta$ - PV drawing machine. Measurements are also taken in relation to air flow, fuel flow, temperature and load measurement. This configuration includes a separate panel box with an air box, fuel tank, pressure gauge, fuel gauge unit and fuel gauges, air flow, function 
indicator and engine indicator. Gyroscopes are provided to measure the flow of cooling water and a calorimeter. Braking Force, Indicated Power, Frictional Power, Brake mean effective pressure (BMEP). An 'Engine, Smooth' laboratory-based machine performance analysis software package is provided for online performance evaluation [15]. The computerized diesel injection pressure path is available as an option. Air flow, fuel flow, temperature and load measurement are expected to be combined. The configuration includes a separate panel box that includes an air box, fuel tank, pressure gauge, fuel gauge unit and fuel and air flow gauges, process indicator and engine indicator. Gyroscopes are provided to measure the flow of cooling water and a calorimeter [16]. Braking Force, Indicated Power, Friction Power, PMEP, IMEP, Brake Heat Performance, Indicated Heat Performance, Engine Performance, Quantitative Efficiency, Specific Fuel Consumption, A / F Rate and This structure allow studying the mechanical performance of the heat balance.

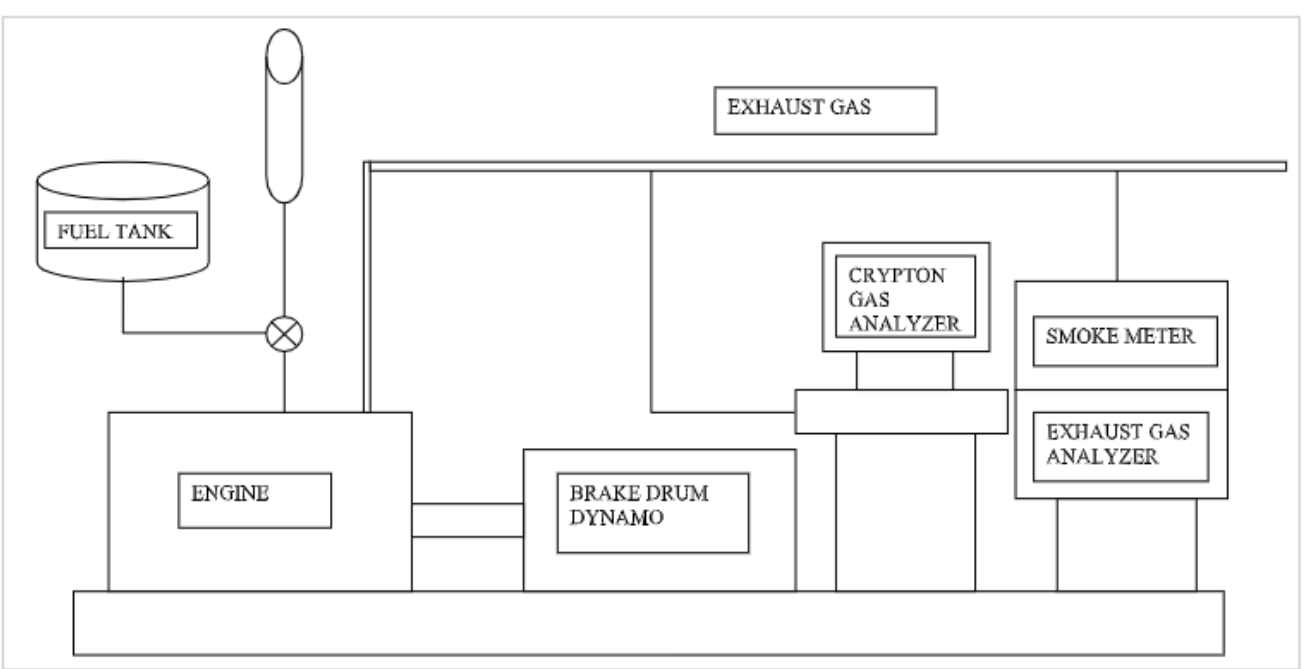

Figure 1 Experimental set up

Table 2 Engine specifications

\begin{tabular}{ll}
\hline Make & KIRLOSKAR OIL ENGINE LTD., \\
\hline Model & SV 1(Computerized) \\
\hline Lubrication oil & SAE40 \\
\hline Lubrication system type & splash type \\
\hline Cooling system & Water cooling system \\
\hline Injection Pressure & $200 \mathrm{bar}$ \\
\hline Stroke & $110 \mathrm{~mm}$ \\
\hline SFC & $250 \mathrm{~g} / \mathrm{kw}-\mathrm{hr}$ \\
\hline Speed & $1800 \mathrm{rpm}$ \\
\hline No. of cylinder & 1 \\
\hline Product code & 224 \\
\hline Bore & $87.5 \mathrm{~mm}$ \\
\hline Max. Power & $8 \mathrm{hp}(5.9 \mathrm{kw})$ \\
\hline Swept Volume & $661 \mathrm{~cm}^{3} \mathrm{or} \mathrm{cc}$ \\
\hline Compression Ratio & $17.5: 1$ \\
\hline
\end{tabular}

\subsection{Experiment procedure}

The engine used in this application is a single cylinder DI (direct injection) diesel engine with 87.5 $\mathrm{mm}$ cylinder bore, $110 \mathrm{~mm}$ stroke and 17.5: 1 compression ratio. This engine can reach speeds of up to $90000 \mathrm{RPH}$. The diesel engine is directly connected to the brake cylinder force meter and the engine power is calculated. At each test, fuel consumption during service and emissions such as carbon monoxide $(\mathrm{CO})$, hydrocarbon $(\mathrm{HC})$, nitrogen 
oxides (NOx), carbon dioxide (CO2), oxygen (O2) and smoke. Preliminary Performance Tests and Graphics Pressure 17.5 with the help of Braking Force (BP), Heat Brake Performance, Specific Fuel Consumption (SFC), Total Fuel Consumption (TFC), Specific Energy Consumption (SEC), Total Energy Consumption (TEC), and the fuel injection pressure is 210 bars for different compounds. The engine ran at constant Revolution per minute (RPM), after which it loaded slowly. Tested with variable load of $0 \%, 25 \%, 50 \%, 75 \%$, and $100 \%$ of $\mathrm{kg}$ load is given to the engine. The engine was established at a fixed speed of diesel and various blends of fuel \& watermelon seed oil. The required fuel time period of $10 \mathrm{cc}$ was recorded using a timer for each mixing and filling. Emissions of carbon dioxide, carbon dioxide and hydrocarbons were measured by a krypton gas analyzer in each compound and smoke emissions were recorded for each compound and group using an AVL smoke meter [17]. Repeat the same process with the melon seed oil and fuel mixture. The properties of diesel fuel and watermelon seed oil blend are listed in the above Table 2. Values were given to illustrate the relevant results and projected on the emission map. The actual viscosity, a point of light, density, flash point and calorific value were calculated in the laboratory.

\section{Results and discussions}

4.1Load with respect to brake thermal efficiency

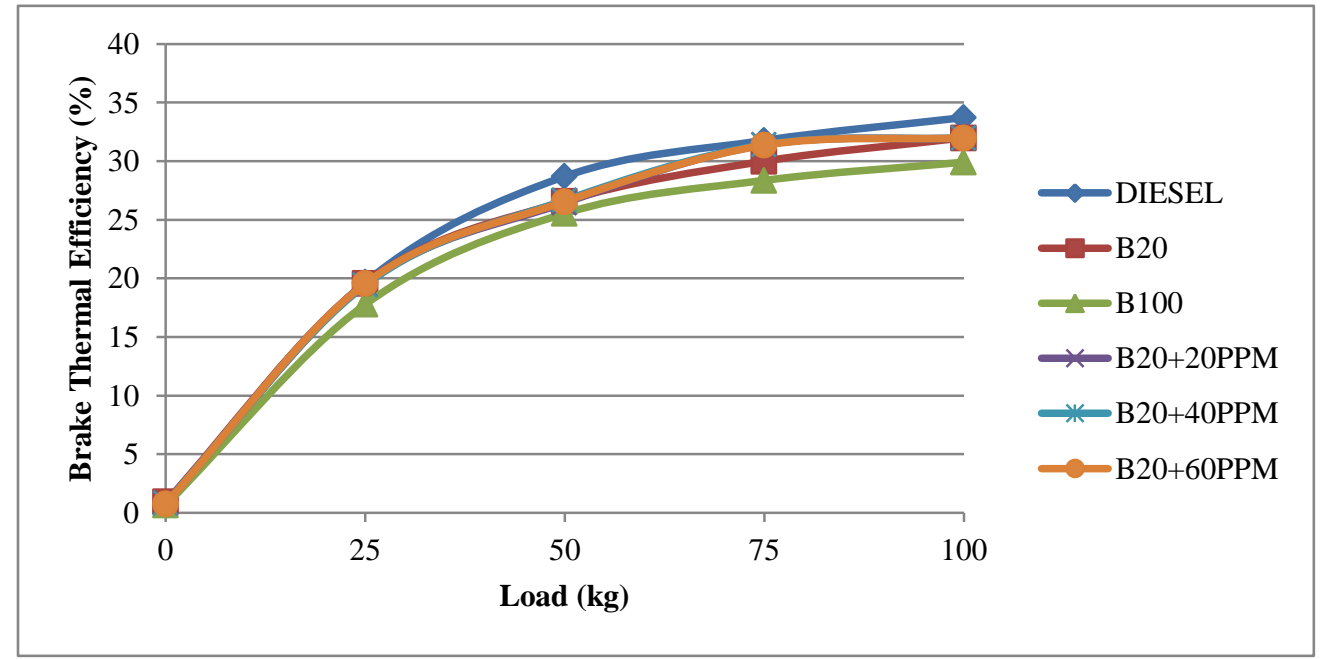

Figure 2 Load with respect to brake thermal efficiency

\subsection{Load with respect to specific fuel consumption}

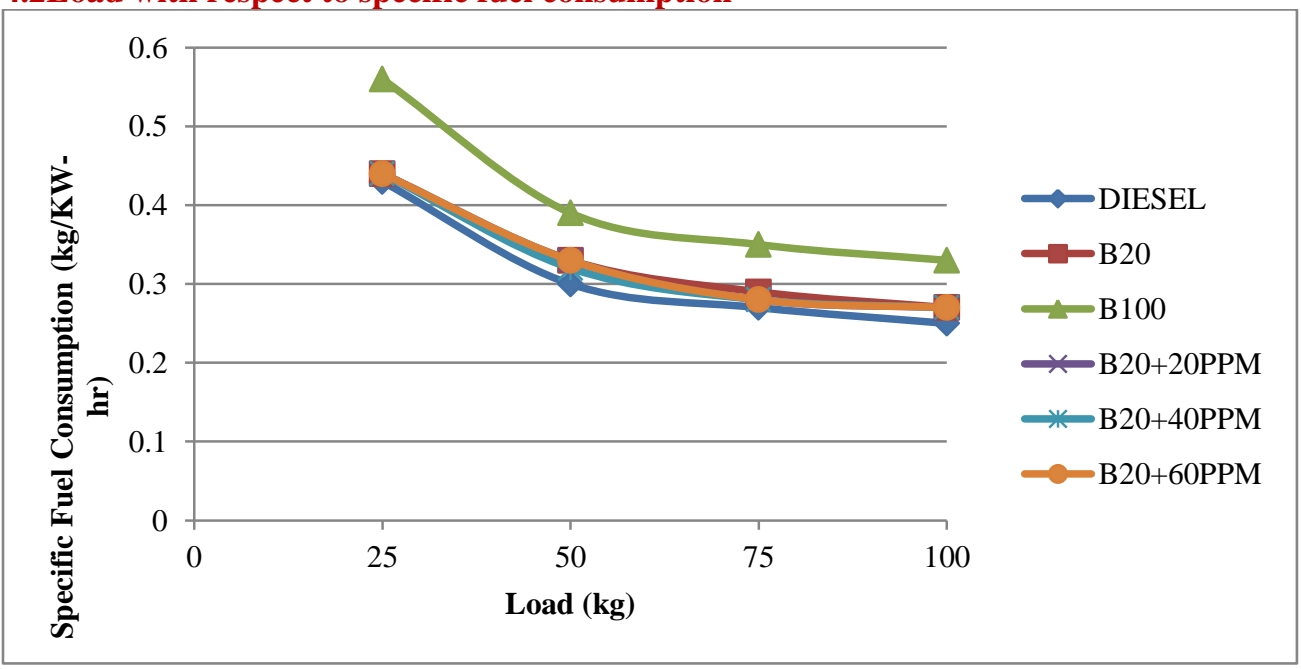

Figure $3 \mathrm{Load}$ with respect to specific fuel consumption 
4.3Load with respect to total fuel consumption

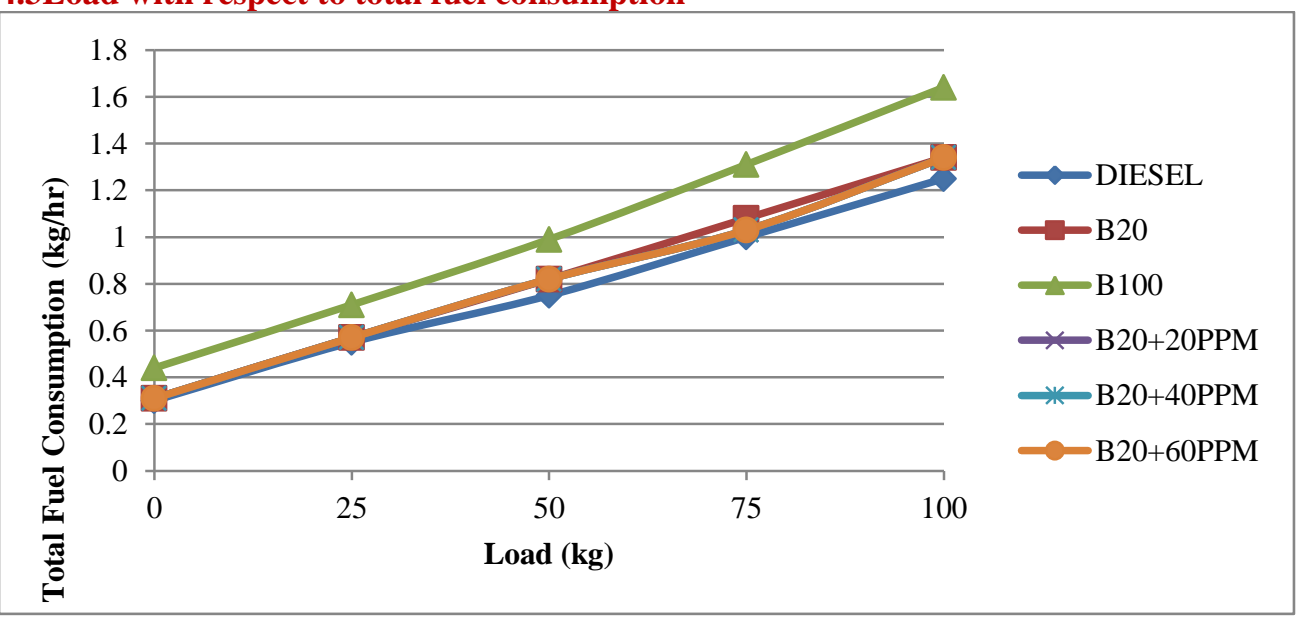

Figure 4 Load with respect to Total fuel consumption

4.4Load with respect to hydro carbon

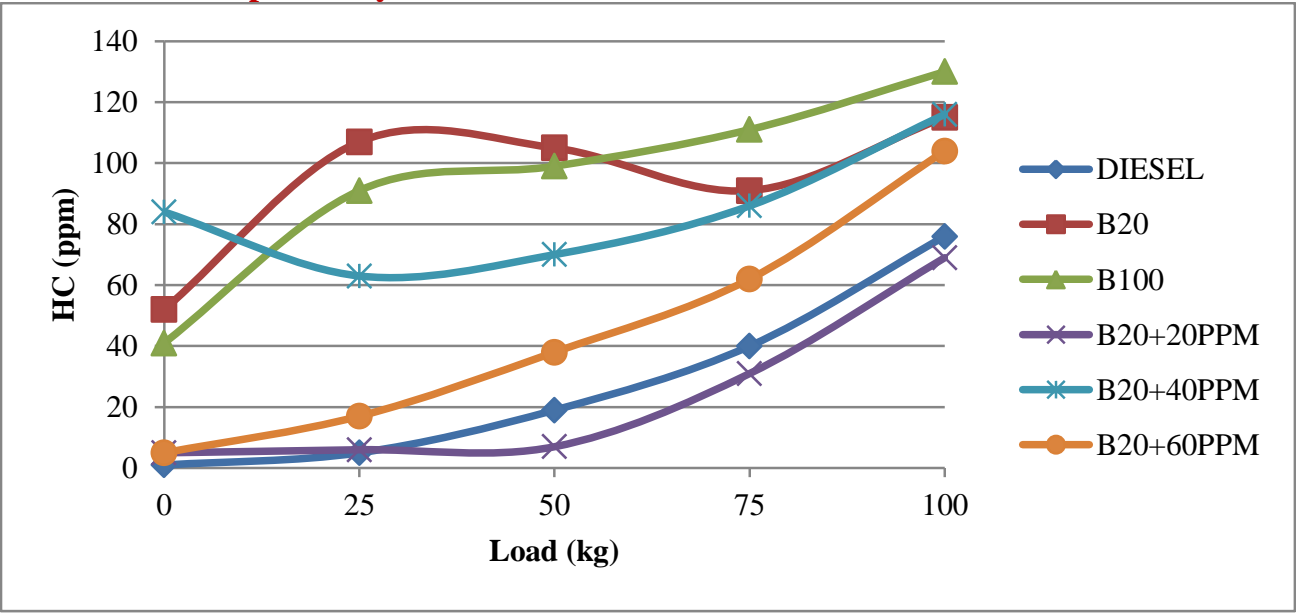

Figure 5 Load with respect to hydrocarbon

\subsection{Load with respect to carbon dioxide}

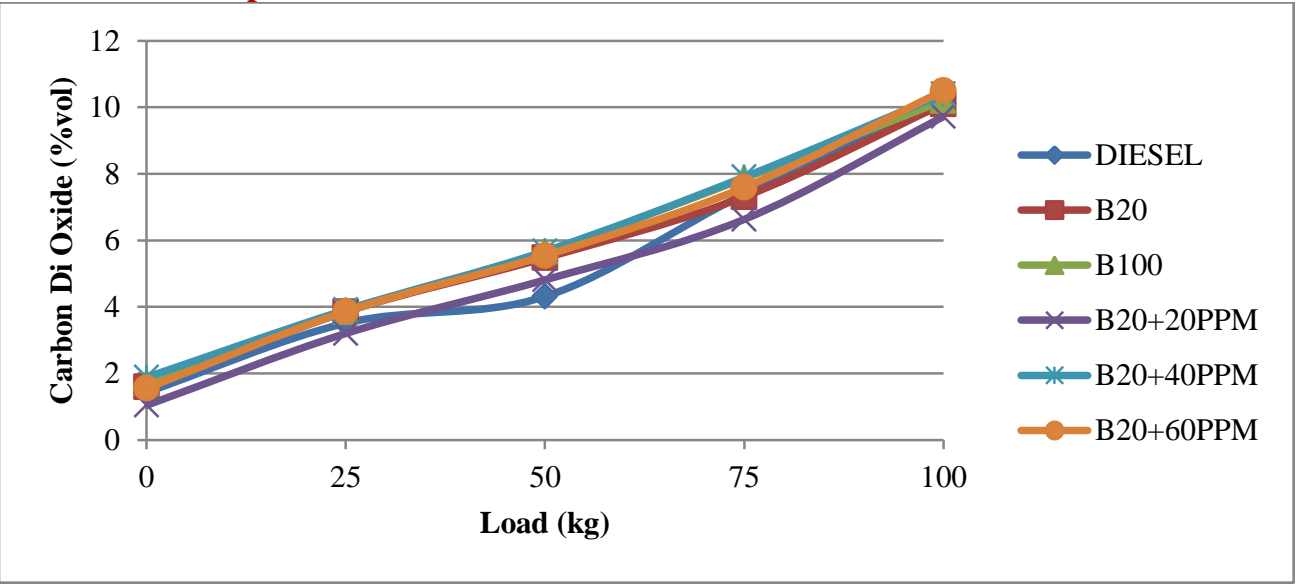

Figure 6 Load with respect to carbon di oxide 
R. Rajasekar and P. Naveenchandran

\subsection{Load with respect to carbon monoxide}

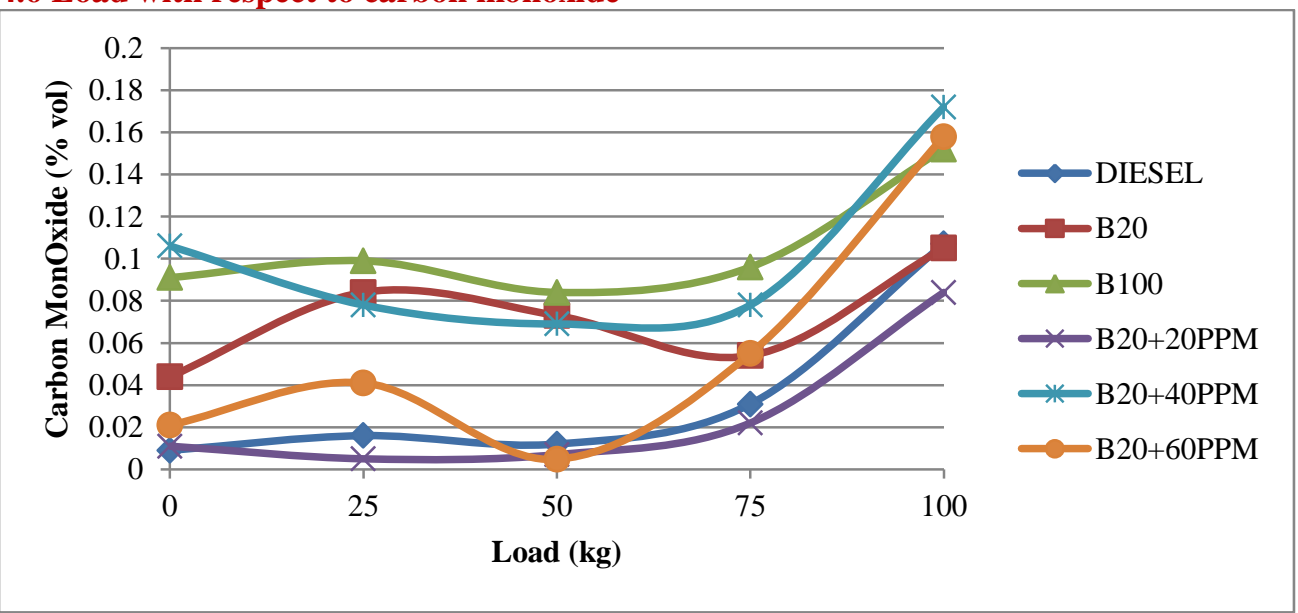

Figure 7 Load with respect to carbon oxide

4.7 Load with respect to nitrogen oxide

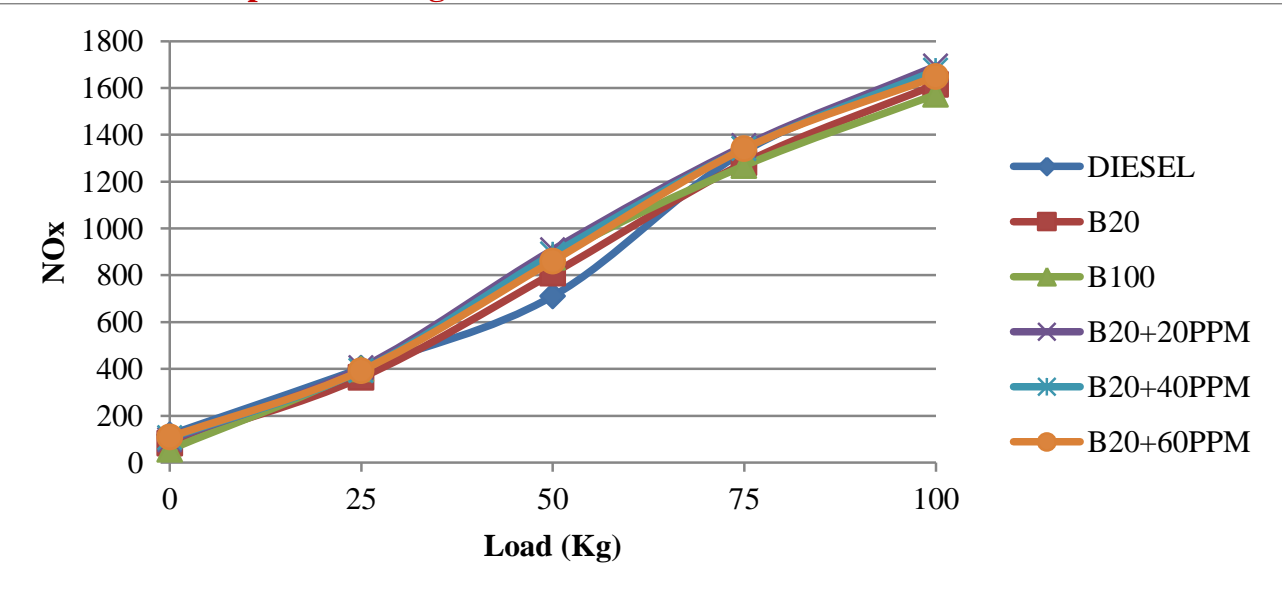

Figure 8 Load with respect to nitrogen oxide

4.8 Load with respect to smoke

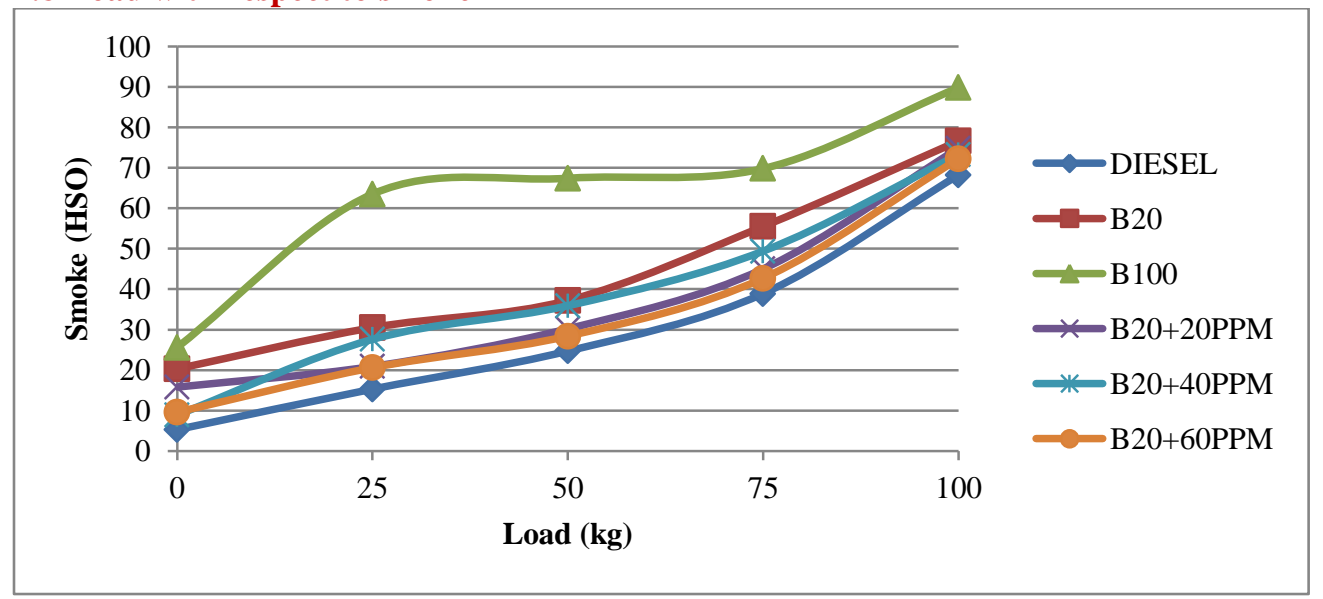

Figure 9 Load with respect to smoke 


\section{Discussions}

5.1Load with respect to brake thermal efficiency Brake thermal performance is defined as the braking control of the heating engine as a role of the heat input of the fuel. Efficiency is used to estimate how well an engine converts heat from the fuel into mechanical energy. The thermal performance of the brakes shows, special fuel efficiency. The performance of the thermal brake is directly opposite to the load [18]. Here we take B20 + 60 ppm, which in this research have a good performance compared to other fuels. The thermal efficiency of the B20 + 60 ppm brakes is 5 percent lower than that of the diesel, and the $\mathrm{B} 20+60 \mathrm{ppm}$ is 3 percent higher than the B20 as shown in Figure 2. This may be due to the difficult viscosity, lower energy content and calorific value is lesser compared to diesel. This leads to reduced decomposition, incomplete combustion and reduced temperature output $[19,20]$.

5.2Load with respect to specific fuel consumption SFC is a considerable fact. Specific fuel consumption for diesel is seen to be higher and increase of 3 percentages comparing to B20 +60 PPM as shown in Figure 3. B20 is a decrease of 1 percentage in B20 +60 PPM. Specific diesel fuel consumption is slightly less than the blends [21]. Additional to the blend, zirconium dioxide nanoparticle decreases SFC due to better atomization of added nanoparticle resulting in better combustion compared to neat diesel and nonnanoparticle combinations. Compared to diesel, may be due to high viscosity. It is poor atomization, and therefore delayed ignition [22].

\subsection{Load with respect to total fuel consumption}

Total fuel consumption is a considerable fact. The total diesel fuel consumption is somewhat less than the blends. Compared to Watermelon seed oil, Diesel has better combustion properties diesel blends as shown in Figure 4. The total fuel consumption of $\mathrm{B} 20+60 \mathrm{PPM}$ is 6 percentage increase compare to diesel and B20 + 60 PPM is a decrease of 2 percentages in B20 [23] Diesel's calorific value is higher than Watermelon seed oil and its blends. Because of this, the total fuel feasting for diesel is minor than the combination of Watermelon seed oil [24].

\subsection{Load with respect to hydrocarbon}

The emission of hydrocarbons increases as the charge increases for all cases as shown in Figure 5. HC emissions are fashioned in the fuel rich region due to the lesser amount of oxygen molecules. As soon as the power of brake also increased, the Hydro Carbon gets increased. It affects the proper formation of mixtures which causes more $\mathrm{HC}$ emissions. The engine's $\mathrm{HC}$ for diesel is seen to be 5 Percentage higher for $\mathrm{B} 20+60$ PPM compared to diesel and $\mathrm{B} 20+60 \mathrm{PPM}$ are decrease of 2 percentages in B20. After about 75 percent load, all the blends showed higher HC emissions [25]. This may be outstanding to poor atomization of the blends of Watermelon seed oil diesel, due to higher viscosity, high density and short volatility. Incomplete combustion of Watermelon seed oil is leading to greater combustion [26].

\subsection{Load with respect to carbon dioxide}

Carbon di-oxide emission is the outcome of incomplete HC combustion, as shown in Figure 6. The $\mathrm{B} 20+60 \mathrm{PPM}$ of $\mathrm{CO} 2$ is 3 percentages higher compared to the diesel and $\mathrm{B} 20+60 \mathrm{PPM}$ is 2 percentage decrease compared to B20. Increasing the loads or mixing with increasing emissions of carbon dioxide [27]. This could be because of the complete combustion. The engine temperature will increase in such a way that combustion will be somewhat good and the $\mathrm{CO}$ will become $\mathrm{CO} 2$.

\subsection{Load with respect to carbon monoxide}

Carbon dioxide emissions are slightly reduced for all biodiesel blends as shown in Figure 7. This is because the carbon content of diesel is lower compared to the carbon content of biodiesel. In this case, $\mathrm{CO} 2$ for $\mathrm{B} 20+60 \mathrm{PPM}$ is 4 percent higher than diesel and $\mathrm{B} 20+60 \mathrm{PPM}$ is 5 percent lower compared to B20. There is no significant difference in $\mathrm{CO} 2$ emissions for all compounds produced compared to diesel fuel at low loading conditions. But for all fuels, $\mathrm{CO}$ emissions increase under higher loading conditions. In comparison, the addition of zirconium nanoparticles has reduced carbon dioxide emissions even under high loading conditions [28]. The shrinkage of the ignition delay is owing to the surface interaction area of the nanoparticles with nanoparticles in the biodiesel and diesel mixture, the fuel-air mixture, the flash evaporation and the nucleus of the fuel spray development.

\subsection{Load with respect to nitrogen oxide}

This figure clearly shows an increase in NOx emissions due to the use of biodiesel as shown in Figure 8. The increase in NOx emissions causes the fat flame to overheat due to the double bonding molecules in the biodiesel fuel. Nitrogen oxide has a 4 percent increase in $\mathrm{B} 20+60 \mathrm{ppm}$ compared to diesel and a 3 percent decrease in B20 + 60 ppm compared to B20. Owing to the adding of 
nanoparticles, the emission of nitrogen oxides increases even with the presence of zirconium nanoparticles here as a catalyst for higher pressure, higher heart rate and oxygen donation [29].

\subsection{Load with respect to smoke}

That reason depends on higher temperatures. It is realized that the diesel engine's smoke opacity of $\mathrm{B} 20+60 \mathrm{PPM}$ is a 3 percent increase of diesel's and $\mathrm{B} 20+60 \mathrm{PPM}$ is decrease 1 percentage in B20 as shown in Figure 9. Owing to the overall productivity of the air fuel ratio, longer duration of the combustion phase and compact oxygen absorption, smoke opacity increases with load increase in engine load. A substantial reduction in smoke emissions is obtained when the biodiesel blends are compared with the neat diesel. The purpose behind this is the disposal of more $\mathrm{O} 2$ molecules in the blend of biodiesel and also in the nanoparticles in zirconium oxide [30].

\section{Conclusion and future work}

This conclusion was drawn from the current study on the performance ratio and emissions analysis of various melon seed oil and diesel mixtures 17.5: 1 is the pressure ratio and a fuel injection pressure of 200 bar. Growing the Zirconium dioxide Nano additives with $60 \mathrm{ppm}$ watermelon seed oil gives better results compared to other readings. The direct injection diesel engine can run on composites without any alteration on the engine setup. Electricity is expected to be cut off owing to the lesser caloric value of watermelon seed oil associated with diesel. The viscosity of watermelon seed oil is higher than that of diesel.

1. The DI diesel engine can run on composites without any alteration on the engine setup.

2. Found to be higher than TFC compounds associated with diesel.

3. SFC \& SEC were found to be higher for blends associated with diesel.

4. The calorific value of watermelon seed oil with additives is lesser than that of diesel and higher than that of B20 and B100.

5. The densities of watermelon seed oil are advanced than that of diesels and lower than that of B20 and B100.

6. Increasing the ratio of watermelon seed oil used in the used diesel / cooking oil mixture decreases the calorific value and viscosity.

7. Owing to the lower calorific value of watermelon seed oil there is an excellent reduction in energy stopping.
8. Of the three blends, the $\mathrm{B} 20+60 \mathrm{ppm}$ has the best performance and emissions results compared to the other performance B20, B100, B20 + 20 ppm and $\mathrm{B} 20+40 \mathrm{ppm}$.

9. $\mathrm{CO} 2$ emissions are higher in the $\mathrm{B} 20+60 \mathrm{PPM}$ mixture than in the diesel.

10. Hydrocarbons and smoke emissions are higher for B20 + 60 ppm alloys compared to diesel.

The future scope of the current research is changing the engine operating parameters such as varying the injection pressure, compression ratio, inlet or exhaust valve timing, changing the piston geometry or biodiesel or Nano additives.

\section{Acknowledgment}

None.

\section{Conflicts of interest}

The authors have no conflicts of interest to declare.

\section{References}

[1] Harari PA. Experimental investigation on the performance and emission characteristics of compression ignition engine fuelled with various blends of water melon biodiesel. Integrated Research Advances. 2017; 4(1):18-23.

[2] Prabakaran B, Udhoji A. Experimental investigation into effects of addition of zinc oxide on performance, combustion and emission characteristics of dieselbiodiesel-ethanol blends in CI engine. Alexandria Engineering Journal. 2016; 55(4):3355-62.

[3] Lujaji F, Bereczky A, Janosi L, Novak C, Mbarawa $M$. Cetane number and thermal properties of vegetable oil, biodiesel, 1-butanol and diesel blends. Journal of Thermal Analysis and Calorimetry. 2010; 102(3):1175-81.

[4] Tyagi OS, Atray N, Kumar B, Datta A. Production, characterization and development of standards for biodiesel-a review. MAPAN. 2010; 25(3):197-218.

[5] Duduyemi O, Adebanjo SA, Oluoti K. Extraction and determination of physico-chemical properties of watermelon seed oil (Citrullus Lanatus L.) for relevant uses. International Journal of Scientific \& Technology Research. 2013; 2(8):66-8.

[6] Ogunwole OA. Production of biodiesel from watermelon (Citrullus lanatus) seed oil. Leonardo Journal of Sciences. 2015.

[7] Ugwuanyi De. Extraction and characterization of watermelon seed oil (Doctoral dissertation). 2011.

[8] Gashaw A, Lakachew A. Production of biodiesel from non edible oil and its properties. International Journal of Science, Environment and Technology. 2014; 3(4):1544-62.

[9] Chattopadhyay S, Karemore A, Das S, Deysarkar A, Sen R. Biocatalytic production of biodiesel from cottonseed oil: standardization of process parameters 
and comparison of fuel characteristics. Applied Energy. 2011; 88(4):1251-6.

[10] Panneerselvam N, Murugesan A, Vijayakumar C, Subramaniam D. Optimization of biodiesel produced from watermelon (Citrullus vulgaris) using batch-type production unit. Energy Sources, Part A: Recovery, Utilization, and Environmental Effects. 2016; 38(16):2343-8.

[11] Asokan MA, Kamesh S, Khan W. Performance, combustion and emission characteristics of diesel engine fuelled with papaya and watermelon seed oil bio-diesel/diesel blends. Energy. 2018; 145:238-45.

[12] Ileri E, Koçar G. Experimental investigation of the effect of antioxidant additives on NOx emissions of a diesel engine using biodiesel. Fuel. 2014; 125:44-9.

[13] Ileri E, Koçar G. Effects of antioxidant additives on engine performance and exhaust emissions of a diesel engine fueled with canola oil methyl ester-diesel blend. Energy Conversion and Management. 2013; 76:145-54.

[14] Bafghi A, Bakhoda H, Chegeni FK. Effects of cerium oxide nanoparticle addition in diesel and dieselbiodiesel blends on the performance characteristics of a CI engine. World Academy of Science, Engineering and Technology, International Journal of Mechanical, Aerospace, Industrial, Mechatronic and Manufacturing Engineering 2015.

[15] Ghanbari M, Najafi G, Ghobadian B, Yusaf T, Carlucci AP, Kiani MK. Performance and emission characteristics of a CI engine using nano particles additives in biodiesel-diesel blends and modeling with GP approach. Fuel. 2017; 202:699-716.

[16] Koçak MS, Ileri E, Utlu Z. Experimental study of emission parameters of biodiesel fuels obtained from canola, hazelnut, and waste cooking oils. Energy \& Fuels. 2007; 21(6):3622-6.

[17] Rakopoulos CD, Dimaratos AM, Giakoumis EG, Rakopoulos DC. Study of turbocharged diesel engine operation, pollutant emissions and combustion noise radiation during starting with bio-diesel or n-butanol diesel fuel blends. Applied Energy. 2011; 88(11):3905-16.

[18] Lujaji F, Kristóf L, Bereczky A, Mbarawa M. Experimental investigation of fuel properties, engine performance, combustion and emissions of blends containing croton oil, butanol, and diesel on a CI engine. Fuel. 2011; 90(2):505-10.

[19] Kannan D, Pachamuthu S, Nabi MN, Hustad JE, Løvås T. Theoretical and experimental investigation of diesel engine performance, combustion and emissions analysis fuelled with the blends of ethanol, diesel and jatropha methyl ester. Energy Conversion and Management. 2012; 53(1):322-31.

[20] Prabu SS, Asokan MA, Prathiba S, Ahmed S, Puthean G. Effect of additives on performance, combustion and emission behavior of preheated palm oil/diesel blends in DI diesel engine. Renewable Energy. 2018; 122:196-205.
[21] Nair JN, Deepthi J, Kalyani K. Study of biodiesel blends and emission characteristics of biodiesel. International Journal of Innovative Research in Science, Engineering and Technology. 2013; 2:37105.

[22] Lalvani JI, Kirubhakaran K, Parthasarathy M, Sabarish R, Annamalai K. Performance characteristics and emission analysis of a single cylinder diesel engine operated on blends of diesel and waste cooking oil. In international conference on energy efficient technologies for sustainability 2013 (pp. 781-5). IEEE.

[23] Ozsezen AN, Canakci M. Determination of performance and combustion characteristics of a diesel engine fueled with canola and waste palm oil methyl esters. Energy Conversion and Management. 2011; 52(1):108-16.

[24] Gnanamoorthi V, Devaradjane G. Effect of compression ratio on the performance, combustion and emission of DI diesel engine fueled with ethanoldiesel blend. Journal of the Energy Institute. 2015; 88(1):19-26.

[25] Tüccar G, Özgür T, Aydın K. Effect of dieselmicroalgae biodiesel-butanol blends on performance and emissions of diesel engine. Fuel. 2014; 132:47-52.

[26] Christopher M, Sabarish R. Emission analysis of a single cylinder DI engine running on biodiesel blend as fuel. Middle East Journal of Scientific Research. 2014; 20(6):681-4.

[27] Surendar S E, Navatha MV. Performance evaluation of four stroke single cylinder c.i engine using diesel and methonal - diesel blended fuel as alternate fuels. International Research Journal of Engineering and Technology. 2015; 2(7): 1267-74.

[28] Atmanl A, Ileri E, Yüksel B. Effects of higher ratios of n-butanol addition to diesel-vegetable oil blends on performance and exhaust emissions of a diesel engine. Journal of the Energy Institute. 2015; 88(3):209-20.

[29] Al-Dawody MF, Bhatti SK. Optimization strategies to reduce the biodiesel NOx effect in diesel engine with experimental verification. Energy Conversion and Management. 2013; 68:96-104.

[30] Akar MA. Performance and emission characteristics of compression ignition engine operating with false flax biodiesel and butanol blends. Advances in Mechanical Engineering. 2016; 8(2):1-7.

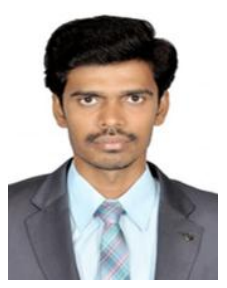

R. Rajasekar, received a Bachelor degree in Automobile engineering in 2013 from Bharath Institute of Higher Education \& Research (BIHER), Chennai, Master degree in Automobile engineering in 2015 from Bharath Institute of Higher Education \& Research (BIHER), Chennai, Currently, $\mathrm{I}$ am doing $\mathrm{PhD}$ in Automobile engineering, Specialization in Alternative fuels, Additives, Vehicle Body.

Email: raja.cachycools@gmail.com 
R. Rajasekar and P. Naveenchandran

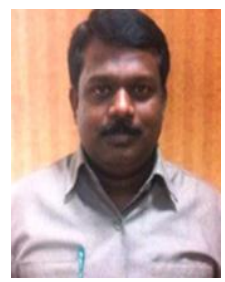

Dr. P. Naveenchandran, received a Bachelor degree in Mechanical Engineering in 1997 from Annamalai University, India, Master degree in Thermal Power in 1998 from Annamalai University, India, and a $\mathrm{PhD}$ on HCCI Engines, from Universiti Teknologi PETRONAS, Malaysia in

2011. I am working as Professor in Automobile engineering Department, with research interests on Alternate fuels, Alternate Combustion Systems and Hybrid Electric Vehicles.

Email: asiriyan@gmail.com 